\title{
Use of Laptops in Internet-Enabled Learning Spaces: Enhancing Electrical Engineering Education
}

\author{
A. Grami, G.S. Rao and M.A. Rosen \\ Faculty of Engineering and Applied Science \\ University of Ontario Institute of Technology \\ 2000 Simcoe Street North \\ Oshawa, Ontario, Canada L1H 7K4
}

\begin{abstract}
The University of Ontario Institute of Technology (UOIT) is Ontario's only laptop university, and among the few universities in the world where every seat in classrooms and laboratories is connected to the Internet, and the faculty are required to appropriately integrate the use of technology into the teaching-learning enterprise. In this paper, we discuss how the use of laptops in Internet-enabled learning spaces can enhance electrical engineering education. Issues of importance are highlighted. The discussions apply to the bachelor program in Electrical Engineering at the UOIT as well as to courses related to electrical engineering that form part of other engineering programs in UOIT's Faculty of Engineering and Applied Science.
\end{abstract}

\section{Introduction}

The University of Ontario Institute of Technology (UOIT) is Canada's newest university, offering select market-oriented and innovative programs. The UOIT is Ontario's only laptop university, and among the few universities in the world where every seat in classrooms and laboratories is connected to the Internet and the faculty are required to appropriately integrate the use of technology into the teachinglearning enterprise. The Faculty of Engineering and Applied Science at the UOIT is offering a bachelor program in Electrical Engineering starting in September 2005.

A vision for the use of laptops was developed and embedded in the overall strategic vision of the UOIT, for their use was seen as providing an opportunity for the introduction of teaching innovations and excellence. To this effect, from its inception in 2003, the UOIT has constantly advanced and extensively utilized mobile technology for teaching and learning.

The emergence and development of information and communication technology (ICT) has increasingly brought tremendous potential and opportunities for educators to enable and deliver learning in ways that could not have been accomplished before [1-6]. This considerable promise in supporting and delivering education over traditional means, however, is not without interesting challenges.

The focus of this paper is to highlight the significant benefits and modest challenges of using state-of-theart ICT in electrical engineering education, while maintaining a balance of technological content and pedagogical rigor. We discuss how preparation and delivery of a course in digital format can be effectively used in classrooms, tutorials and labs to help students learn more easily and effectively and understand complex concepts faster, yet with longer lasting effects.

\section{Laptop program at UOIT}

Every student at the UOIT has a laptop PC and every engineering faculty member has a tablet PC, all with specialized software to meet the needs of specific academic programs. This approach has the sole purpose of advancing markedly the effectiveness of university education - through enhancing students' learning and instructors' teaching capabilities.

Table 1 presents features associated with the laptops for engineering students. At the UOIT, learning spaces, such as classrooms, labs and tutorial rooms, 
equipped with large electronic projection and multimedia support, are all fully networked, so every seat is connected to the $1 \mathrm{Gbps}$ wired Ethernet LAN, and study rooms, library, and common areas can be all connected to the data networks using laptops' built-in wireless 55-Mbps IEEE-802.11g cards. In addition, the university has expanded teaching and learning through WebCT, an e-learning system through which interactive course materials of all types of modalities can be delivered to students through the Internet, as well as a forum through which students can engage in online discussions.

UOIT furnishes all engineering students with the same laptops. The program fee of about $\$ 1500$ a year is incorporated with the university tuition fee. Students use laptops for note-taking, research capabilities, collaborative project development, program-specific software applications, online tests and exams, spreadsheet and database resources and applications. They also access the university online learning management system and portal services, which are an integral part of all UOIT courses.

Every student is responsible for the care of the laptop's hardware and software, compliance with the licensing agreement for the software and the university policy for IT, and back up of all personal data. However, the university IT services provides configuration assistance, training seminars, and hardware and software problem resolution.

\section{Learning technologies in electrical engineering education}

It is expected that our Electrical Engineering laptopbased program will attract a number of technologically elite (technophile) students and a group of technological neophytes, and others in between. All must meet the admission requirements. The goal to use ICT in Electrical Engineering education is to strike a reasonable balance between theoretical and practical aspects to meet the curriculum and course requirements. Another requirement is to satisfy the criteria of the Canadian Engineering Accreditation Board (CEAB). Use of ICT can greatly change how engineering students learn, making it more efficient and effective, as well as how instructor and student time can be effectively utilized. Also as a side advantage, use of ICT can help students to be fully comfortable and competent with the enhanced computational capabilities, modeling and simulation, and other software tools available, thus making them, upon graduation, more attractive to potential employers.
Electrical Engineering is a broad discipline, constituting of diverse areas of specialization, such as electronics, power, control, communications, computer, and biomedical engineering. About half of the courses in the undergraduate curriculum are electrical engineering based, and the other half are mathematics, science, professional, and liberal studies courses. Learning technologies are meaningfully integrated into education, and diffused throughout the program, not for their own sake or novelty, but with the expectation of more, better, and different learning. ICT can enhance learning when the pedagogy is sound, and when there is good match of educational technology, learning styles, outcomes and participation. Instructors - whether they are innovators in using ICT or not-will adopt, adapt, and eventually learn to use technology effortlessly and creatively, should their time and effort in designing courses to simulate interactive teaching and cooperative learning be encouraged, acknowledged and rewarded.

Before embarking on a discussion of what the learning technologies are, how and when they should be utilized to significantly enrich students' learning in an Electrical Engineering program (as summarized in Table 2 and described in this section), it is emphasized that, should the need arise, instructors use the blackor white-boards to help students learn. In short, use of learning technologies does not preclude use of traditional means of teaching. However, in general, instructors use their tablet PCs to address questions and explain concepts, and afterwards they save this material and post it on WebCT. This approach is more so for theoretical courses, such as Fundamentals of Electromagnetics, Probability and Random Signals, and Complex Analysis, which may require detailed mathematical derivations. WebCT is a leading fullfeatured course management system that provides faculty with a range of tools - which include private email, bulletin board, chat, surveys, quizzes, grade maintenance, progress tracking, glossary and index, and content searches. Students have access to lecture notes, on-line tutorials, assignments, lab manuals, testbanks and video tapes.

Lectures in almost all courses utilize PowerPoint presentations. The PowerPoint presentations consist of a series of slides highlighting the course content and incorporating key points from the text, and generally include figures and tables as appropriate, all with a view to creating interesting and engaging classroom presentations. If not used carefully, PowerPoint presentations can be viewed by students simply as boring and a mere convenience for instructors. PowerPoint presentations can be even more powerful if voice narrated, then a student who misses a part of 
what the instructor is saying can pick it up later by going through the presentation again. Also, featurerich, easy-to-learn and easy-to-use software packages for accurate system simulation and mathematical analysis, such as MultiSim and Matlab, are used primarily in tutorials for core courses. These packages allow students to create circuits, analyze pre-built circuits, work through virtual laboratory assignments, simulate circuit behaviour and troubleshoot for faults. More sophisticated software packages, such as LabView, can be utilized in advanced courses such as Modern Control Systems with specialized lab requirements and equipment.

Online learning centers - which have been designed to provide a wide variety of learning opportunities for students, such as e-books and self-quizzes - are fully utilized by students throughout the semester, on their own time and at their own pace. In fact, a meaningful criterion for the selection of a textbook is how rich its online learning center is. Also, the Internet is widely utilized to provide refereed and updated research links, course-specific current articles in news media refereed by content experts, and the latest papers in refereed journal publications. Students initially believe whatever they find on the web is true and valid. Thus, instructors need to provide a great deal of direction, so the students can find out on their own what websites are valuable and are worth referring to, such as websites representing MIT courseware and IEEE databases.

Interactive videos and animation, usually in courses which are descriptive and have no lab components, are shown to expand the reach and scope of the course content. For instance, in Information Technology, Impact of Science and Technology on Society, and Professional Engineering (Economics, Law and Ethics) courses, topics of interest and case studies are discussed, all with a goal to inspiring discussion and testing students' critical thinking skills through a variety of thought-provoking questions. Also, video vignettes show the students how various real-world large physical equipment can function, something that cannot be physically demonstrated in university labs. For instance, they could be on cellular base stations, microwave towers, TV and radio broadcasting stations, and telephone central offices for the Communication Systems course, or on power generation plants, transmission lines, and substations for the Power Systems course. They can also present the production of highly-complex integrated-circuits (IC) chips, nanotechnology, and space-qualified products, all with a view to helping students appreciate end-to-end systems and get the proper perspective.
The integration of Java-based applets with lecture notes greatly enhances the presentation of the course material by allowing students to experience the underlying components of complex concepts in action, rather than merely by description (talked in class, written on board, or presented on screen). These applets, available on the text's CD-ROM, CLOE and MERLOT repositories or certain websites advanced by educators, provide virtual laboratory experiments, and are not just simple demonstrations, but in fact are tools that enable students to vary one or more parameters and observe the results. It is usually advantageous for students to have their laptops in a class or a tutorial, as they can, after a complex concept has been discussed, use these applets to further understand it, either on their own or under the instructor's direction. Specifically, the students can use their Java-based applets to understand the relationships between the physical and the abstract. Some examples for courses follow: i) in Signals and Systems, students grasp abstract concepts, such as sampling theorem and analog-to-digital conversion, through physical realizations of sounds and images, simply by changing one parameter (and sometimes few simultaneously) to the see the impact of parametric changes on the audio and visual performance and perception; ii) in Digital Signal Processing, students change the type and the complexity (e.g., the number of taps and feedbacks) of the digital filter, and thus appreciate how the frequency (amplitude and phase) response can accordingly change, and realize the interdependence among various parameters and variables and how to tailor the response and assess the filter complexity; iii) in Communication Systems, students experience the impact of bandwidth and noise in digital data transmission to see the data detection performance in band-limited and noisy systems, as well as appreciate Nyquist-I Criterion by employing various signal shapes and roll-off factors in distorted channels; iv) in Multimedia Systems, students demonstrate the means by which images are processed and reproduced as well as the visual effects of some types of processing and data compression, for which examples may include run-length lossless or lossy image compression algorithms, image color encoding and resolution; v) in Wireless Communications, students assess the impact of multipath fading, Doppler effect, and other types of mobile channel degradations on speech and image quality, and evaluate the role of various channel coding schemes on performance. Also, as highlighted in the next section, applets can be extensively used in Electric Circuits, Introductory Electronics and Electronic Circuit Design courses to analyze the 
performance of passive and active circuits, gauge their complexities, understand tradeoffs, and gain insights.

\section{Learning technologies in electrical engineering labs}

In order to illustrate the use of learning technologies in electrical engineering labs, as a case study, we now focus on the lab for Electric Circuit course, a mandatory course not only for Electrical Engineering students, but also for all engineering students. The UOIT believes a curriculum integrated e-learning program will provide learning experiences that develop higher order of thinking skills and enhance creativity. The laboratory equipment is procured to support this philosophy. Equipment acquired is required to be compatible with and provide good interfacing for the laptops and e-learning program. The laboratory is to support all Electronics courses offered in the Electrical Engineering program, including the basic engineering Electric Circuits course. Each workstation has an Agilent Digital Storage Oscilloscope, an Agilent Waveform Generator, an Agilent Desktop Digital Multimeter, a Handheld Digital Multimeter, an Agilent 3-Output Power Supply, and a full-featured desktop PC. All instrumentation equipment is connected and can be controlled by a computer via a General Purpose Interface Bus (GPIB). The GPIB port is also connected to USB port of workstation PC. Students can capture data from the laboratory instrumentation directly to their laptops by plugging the USB cable or transfer data files from the laboratory PC through the campus local area network. The laboratory PC is loaded with a number of simulation packages, such as MultiSim, Maple-TA, LabView and other office applications software. The intent of augmenting the curriculum with these packages is to enhance the students' theoretical understanding of the material with hands on analysis and design experience. Our goal of providing comprehensive learning tools incorporating modern ICT technologies starts with the selection of the simulation packages and the textbook. A textbook requires a virtual instrumentation package supporting instrumentation equipment. Students find it very helpful as they can practice with these virtual instruments especially the oscilloscope, function generator and digital multimeter without stepping into the laboratory.

Students generally have a difficult time understanding the functional aspects of electrical circuits in that they are difficult to visualize. Students' difficulties are often compounded by traditional instructional methods that fail to engage them in the classroom. One instructional strategy that helps engineering students go deeper in their thinking about the functional aspects of electrical circuits is showing these effects with the help of simulation packages. MultiSim is a powerful simulation tool for circuits and systems, which also co-simulates SPICE simulator and RF devices so students can analyze complete boards containing various devices, verify circuits, and locate errors, before they propagate further down the design flow and become costly mistakes. For instance, students can quickly study the behavior of an RC circuit by varying the values of the components, which in turn initiates various discussions related to magnitude response and phase response. Students can also reverse the placements of the $\mathrm{R}$ and $\mathrm{C}$ components and observe the circuit behavior. Students can use Matlab scripts to plot the frequency response (Bode plot) of the circuits. Tutorial sessions also encourage students not only find the solution of a circuit by hand, but also to do so using MultiSim or Matlab. In fact, most students use simulation packages to verify their homework problems. Even weak students show a high degree of interest, and more readily contribute to class discussion.

Electric Circuits laboratory sessions are designed to be an active learning experience: learning from doing and observing as opposed to listening to lectures and solving idealized circuit problems. Students are given the opportunity to observe the circuit behavior in realtime and obtain an understanding how circuits behave and theory has come about. Eight laboratory experiments are included in the lab. A procedure is developed for students in conducting the experiments. A video clip is produced showing how to connect various instruments to the circuit including the data collection process, and is made available on the campus network. Students can view the video clip while conducting the experiments. Each experiment also comes with a video clip so that students with their headphones can start assembling the circuit by following the principles.

A significant part of the laboratory is pre-lab which consists of a number of designs and circuit behavior problems. The pre-lab tasks require the use of various simulation packages. It is mandatory for the students to complete all the tasks required in the pre-lab before coming to the laboratory. As a part of pre-lab, students are also directed to learn from online, freely available applets and compare the results with simulation models developed by them. For example, the transient response of an $\mathrm{RC}$ circuit applet available at http://www.phy.ntnu.edu.tw/java/rc/rc.html can show very clearly how an RC circuit behaves when a switch changes positions. As shown in Fig. 1, this Java applet shows the transient behavior that occurs when the 
capacitor is being charged and discharged. Students can then run a simulation model on their laptops (see Fig. 2) and see how their model compares with that observed online. Students require very little help as they are forced to learn most of the skills and theory needed before coming to the laboratory. As the laboratory instruments are programmable, students can capture data from the digital multimeter, oscilloscope or a function generator and verify or analyze the data. As the necessary data manipulating tools are readily available on their laptops, students can check their work by comparing the expected results form the pre-lab worksheets. Students can revisit their experiment procedures when they find the experimental results do not match the theoretical expectations, on their own rather than being verified by the TA. One of the significant advantages in using the laptops is that students can check their results and repeat the experiment, if required.

\section{Learning technologies: challenges}

Research supports the use of technology as a catalyst for improving the learning environment; however, bringing the laptops to Internet-enabled classrooms and their use by students during the lectures can create a challenge for the instructor regarding how to channel students' attention exclusively to the class and to what he or she is discussing. In other words, e-distraction, i.e., use of laptops by students for entertainment purposes (e.g., sending e-mails, watching videogames), is an everpresent problem in classrooms which, though it cannot be eliminated, needs to be minimized. One option is to ask all students to close the lid; this would certainly solve the problem, however, by no means would that be sufficient to bring back students' attention to the classroom. In addition, students would generally resent not being permitted to use the laptops when they have paid for them, and having the actions of some should result in a ban for all. Another option is to employ a passive role, that is, to disregard the lack of attention by some students, i.e., let some students wander in cyberspace. This of course defeats the purpose of using technologies to enhance learning in the first place, and ignores research indicating a high correlation between memory and the passivity of the learning involvement, for students can remember a lot better what they actively say and do in class as opposed to what they passively hear and see.

E-distraction in class, which is disrespectful to the instructor and fellow students, may occur for a variety of reasons: i) some students may not like the subject matter or find the course content difficult, resulting in lack of interests in the course and class activities; ii) students typically have very short attention spans, i.e., they get bored quickly; iii) large classes are often impersonal and non-engaging; and iv) instructors fail to incorporate interactive multimedia teaching tools into course activities. To avoid problems, as a first step, the instructor should highlight the rules of use of laptops and the Internet in his or her course outline, and discuss them in detail in the first lecture. More importantly, the instructor must take an active role in teaching and learning, i.e., changing the way and the means of teaching with the aim to keeping lectures interesting, while educational-for instance, shifting from a PowerPoint presentation to learning objects to interactive video to the blackboard. During a lecture, there is always a constant need to get students actively involved in problem solving, creative thinking, design innovation, and system analysis using learning and teaching technologies through various modalities and platforms.

Regular lecture attendance is also an interesting challenge, for in principle it is not mandatory. This has become a problem simply because the class notes, which constitute everything the instructor shows on the screen and writes on the tablet PC, are available on WebCT. In response to the poor attendance that can result, students should be repeatedly informed by various means (e.g., e-mails) that certain topics may be discussed in class-say an answer to or a discussion following a student's question — which may not be put on WebCT at a later time. In addition, the students should know that the sequence of events in class (from slide presentation to writing on board to a pop-quiz to a video clip) and the informal interactive discussions matter, and without attending the lectures, they will never know of them, let alone learn them, and yet they may be tested on them.

Another challenge is academic dishonesty. It is imperative to repeatedly remind students that ethics is an indispensable core value in engineering and unethical behaviour, or a perception of it, is not tolerated. Cheating on tests and final exams can be almost eliminated by holding them where students can be widely spread out and carefully invigilated, along with holding secure exams where students cannot use the Internet or any source of information on their laptops. The more frequent form of academic dishonesty is plagiarism, where some students may hand in an assignment or a lab report, in which a part or all of it has been copied. Digital plagiarism can occur quite frequently, for the work of others can be easily obtained electronically and, after fonts, formats and other cosmetic changes have been made, can be submitted. To deter plagiarism, the following approaches should be simultaneously taken: i) allocate 
only a modest portion of the final mark to what students hand in during the semester, ii) give students enough time to do an assignment or a lab report either by themselves or through help from an instructor or a tutor, iii) inform students that parts of tests and the final exam will include problems similar or identical to those on assignments, and iv) make sure students are fully aware of the potential consequences of academic misconduct.

\section{Closure}

The UOIT appears to be one of the pioneering universities in advancing the appropriate use of ICT in teaching and learning. Learning technologies can be well integrated into electrical engineering education, and diffused throughout the program. It is highly anticipated that the use of ICT will help lead to more effective teaching and better learning outcomes. However, ICT integration into engineering education is still in its infancy stage. Its evolution will be shaped by i) the emerging cheaper, smaller and faster computers with more capabilities and capacities, ii) the more sophisticated learning objects and educational multimedia packages advanced by publishers and educators, iii) advanced interactive mathematical and simulation software packages, and iv) the publication of the valuable experiences gathered by the instructors and feedbacks provided by the students.

\section{References}

[1] E.R. Doering, "Electronics Lab Bench in a Laptop: using Electronics Workbench to Enhance Learning in an Introductory Circuits Course", in Proceedings of Frontiers in Education Conference, pp. 18-21, Pittsburgh, November 1997.

[2] W.F. Moss, "Laptops in the Engineering and Science Classroom", in Proceedings of Engineering Conference International Symposium Series, pp. 1-3, Switzerland, August 2002.

[3] B.L. Crynes, "Universal Student Computer AccessRequiring Engineering Students to Own Computers," Journal of Engineering Education, Vol. 86, No. 10, pp. 301-304, October 1997.

[4] M. Kadiyala and B.L. Crynes, "A Review of Literature on Effectiveness of Use of Information Technology in Education", Journal of Engineering Education, Vol. 89, No. 2, pp. 177-184, (2000).

[5] M.S. Zywno, "Instructional Technology, Learning Styles and Academic Achievement", Proceedings of 2002 ASEE Annual Conference and Exposition, Session 2422, Montreal, Quebec, June 2002.

[6] D.L. Shirley, C.L. Pierson, D.A. Trytten, T.R. Rhoads, and M.A. Court, "A Laptop College of Engineering at the University of Oklahoma," Proceedings of Frontiers in Education Conference, pp. F1F1-6, Boston, November 2002.

Table 1. Laptop features for UOIT engineering students

\begin{tabular}{|l|l|}
\hline Model & IBM R51 \\
\hline CPU & PM 1.6 GHz \\
\hline Memory & $512 \mathrm{MB}$ \\
\hline Video & $32 \mathrm{MB}$ ATI Mobility RADEON 9000 \\
\hline Disk & $60 \mathrm{~GB}$ \\
\hline Media & CD-RW/DVD \\
\hline Screen & $15 "$ XGA 1024 x 768 \\
\hline Mouse & Touchpad/TrackPoint \\
\hline Network & $56 \mathrm{~K}$ modem, 1 Gbps wired Ethernet, wireless IEEE-802.11a/b/g cards \\
\hline Sound card & Sound Blaster compatible, 2 built-in speakers (stereo) \\
\hline Warranty & 2 years \\
\hline
\end{tabular}


Table 2. Uses for learning and teaching technologies

\begin{tabular}{|l|c|c|c|c|}
\hline Learning and Teaching Technologies & Lectures & Tutorials & Labs & Home \\
\hline Power-Point Presentations (w/o voice-annotation/audio-insertion) & $\mathrm{X}$ & & & $\mathrm{X}$ \\
\hline Simulation Software Packages (e.g., MultiSim, LabView) & $\mathrm{X}$ & $\mathrm{X}$ & $\mathrm{X}$ & $\mathrm{X}$ \\
\hline Mathematical Software Packages (e.g., Matlab, Maple-TA) & $\mathrm{X}$ & $\mathrm{X}$ & $\mathrm{X}$ & $\mathrm{X}$ \\
\hline Online Learning Centre (e-book, student's solutions manual, test-bank) & & $\mathrm{X}$ & & $\mathrm{X}$ \\
\hline Worldwide Web (e.g., MIT courseware, IEEE databases) & & $\mathrm{X}$ & & $\mathrm{X}$ \\
\hline Learning Objects (e.g., CD-ROM, CLOE, MERLOT repositories) & $\mathrm{X}$ & $\mathrm{X}$ & $\mathrm{X}$ & $\mathrm{X}$ \\
\hline Interactive Video \& Animation & $\mathrm{X}$ & & & $\mathrm{X}$ \\
\hline Video Vignettes & $\mathrm{X}$ & & $\mathrm{X}$ & $\mathrm{X}$ \\
\hline WebCT (e-mails, discussions, assignments, labs, lectures, self-quizzes) & $\mathrm{X}$ & $\mathrm{X}$ & $\mathrm{X}$ & $\mathrm{X}$ \\
\hline
\end{tabular}
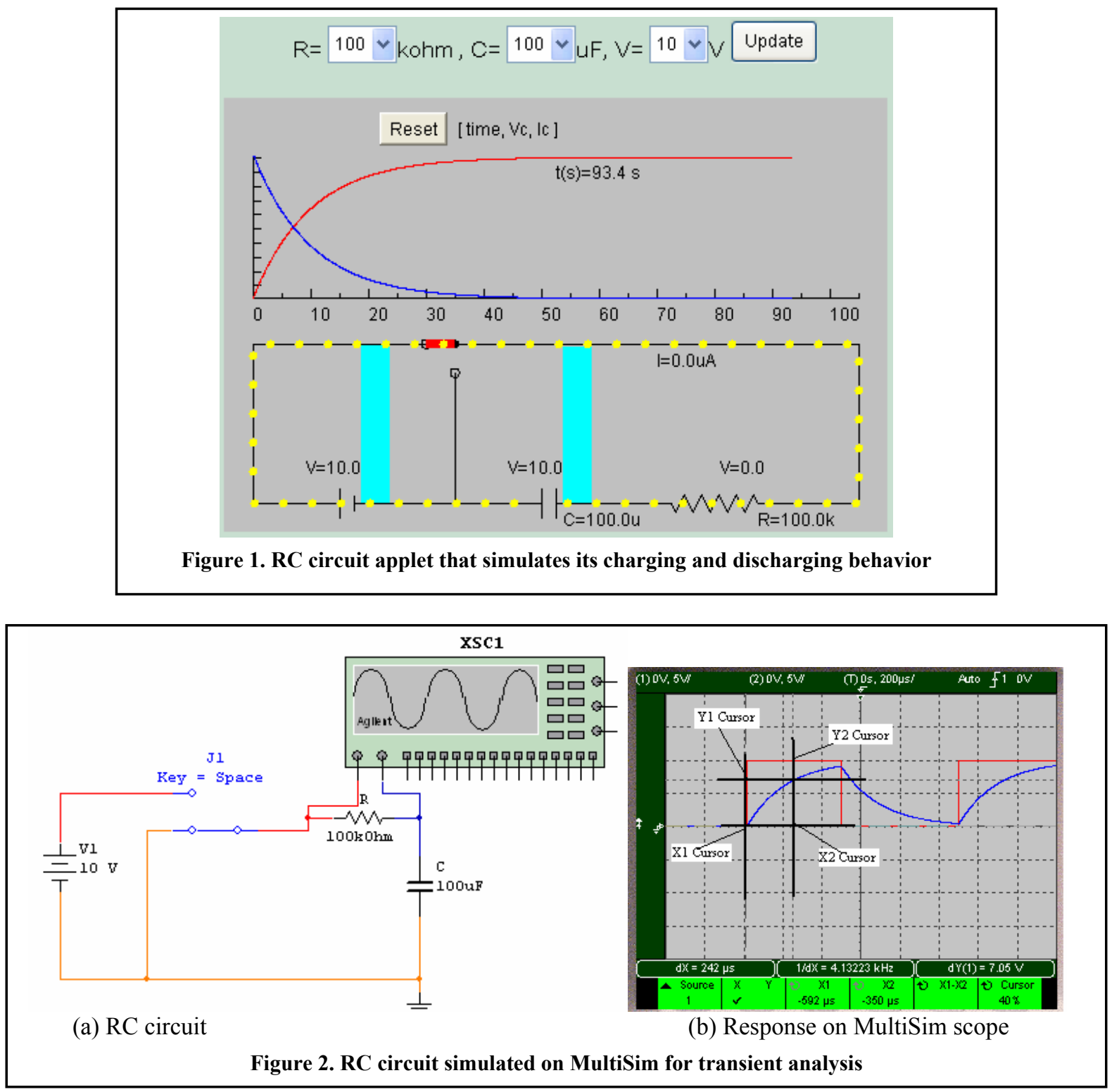